\title{
Cortisol and Cortisone in Early Childhood in Very-Low-Birthweight Infants and Term-Born Infants
}

\author{
Miranda de Jong ${ }^{\mathrm{a}} \quad$ Anneke Cranendonk $^{\mathrm{b}} \quad$ Jos W.R. Twisk ${ }^{\mathrm{c}}$ \\ Mirjam M. van Weissenbruch ${ }^{b}$ \\ aDepartment of Pediatrics, Albert Schweitzer Hospital, Dordrecht, The Netherlands; ${ }^{b}$ Department of Neonatology, \\ Emma Children's Hospital, Amsterdam UMC, Vrije Universiteit Amsterdam, Amsterdam, The Netherlands; \\ 'Department of Clinical Epidemiology and Biostatistics, Amsterdam UMC, Vrije Universiteit Amsterdam, Amsterdam, \\ The Netherlands
}

\section{Keywords \\ Cortisol · Cortisone $\cdot 11 \beta$-hydroxysteroid dehydrogenase type $2 \cdot$ Metabolic syndrome · Preterm infants}

\begin{abstract}
Introduction: Besides programming of the hypothalamicpituitary-adrenal (HPA) axis, changes in the activity of $11 \beta$ hydroxysteroid dehydrogenase type 2 (11 $\beta$-HSD2) could contribute to the later metabolic and cardiovascular consequences of preterm birth. Objective: We compared serum cortisol, cortisone, and cortisol/cortisone ratio in early childhood in very-low-birthweight (VLBW) infants and term appropriate for gestational age (AGA) born infants. Methods: We included 41 VLBW infants, participating in the randomized controlled Neonatal Insulin Replacement Therapy in Europe trial, and 64 term AGA-born infants. Cortisol and cortisone were measured in blood samples taken at 6 months and 2 years corrected age (VLBW children) and at 3 months and 1 and 2 years (term children). At 2 years of (corrected) age (HDL) cholesterol, triglycerides, glucose, and insulin were also measured. Results: During the first 2 years of life, cortisol/cortisone ratio is higher in VLBW children compared to term children. In the total group of children, cortisol/cor-
\end{abstract}

tisone ratio is positively related to triglycerides at 2 years of (corrected) age. In VLBW children, over the first 2 years of life both cortisol and cortisone are higher in the early-insulin group compared to the standard care group. Conclusions: In VLBW infants, lower $11 \beta-H S D 2$ activity probably contributes to the long-term metabolic and cardiovascular risks. In VLBW infants, early insulin treatment could affect programming of the HPA axis, resulting in higher cortisol and cortisone levels during early childhood.

(c) 2021 The Author(s)

Published by S. Karger AG, Basel

\section{Introduction}

Programming of the hypothalamic-pituitary-adrenal (HPA) axis plays an important role in the association between intra-uterine growth restriction (IUGR) and/or preterm birth and higher blood pressure in later life. Very-low-birthweight (VLBW) infants have a high prevalence of raised blood pressure already in early childhood [1-3], and we earlier showed that at the corrected age of 2 years, cortisol levels are positively correlated to blood pressure in VLBW boys [4]. karger@karger.com www.karger.com/hrp

Karger $\stackrel{\text { ' }}{5}$

BOPEN ACCESS
(C) 2021 The Author(s)

Published by S. Karger AG, Basel

This is an Open Access article licensed under the Creative Commons Attribution-NonCommercial-4.0 International License (CC BY-NC) (http://www.karger.com/Services/OpenAccessLicense), applicable to the online version of the article only. Usage and distribution for commercial purposes requires written permission.
Mirjam M. van Weissenbruch

Department of Neonatology, Emma Children's Hospital, Amsterdam UMC Vrije Universiteit Amsterdam

PO Box 7057, NL-1007 MB Amsterdam (The Netherlands)

m.vanweissenbruch@amsterdamumc.nl 
Studies in IUGR-born children suggest that changes in the activity of $11 \beta$-hydroxysteroid dehydrogenase type 2 (11 $\beta$-HSD2) contribute to the metabolic and cardiovascular consequences in later life $[5,6]$. 11 $\beta$-HSD2 converts cortisol into inactive cortisone and is mainly active in the kidney [7]. In children born with IUGR and without catch-up growth, cortisol (F)/cortisone (E) ratio at the mean age of 7 years was significantly higher compared to controls, suggesting a partial $11 \beta-\mathrm{HSD} 2$ deficit [5]. In these children, F/E ratio was positively correlated with cholesterol levels, indicating a risk factor for cardiovascular disease [5]. We hypothesize that changes in $11 \beta$-HSD2 activity could also contribute to the later consequences of preterm birth.

The aim of the present study was to compare serum cortisol, cortisone, and F/E ratio in infancy and early childhood in VLBW infants (birthweight $<1,500 \mathrm{~g}$ ) to term appropriate for gestational age (AGA)-born infants. The VLBW children were part of the Neonatal Insulin Replacement Therapy in Europe (NIRTURE) trial [8]. We showed earlier that at 2-year corrected age, insulintreated children had higher serum cortisol levels than children in the standard care group [4]. In the present study we also evaluate the effect of early insulin therapy on serum cortisone and $\mathrm{F} / \mathrm{E}$ ratio.

The third aim was to investigate the relationship between F/E ratio and components of the metabolic syndrome at 2-year (corrected) age in the total group of children (VLBW and term AGA). The cortisol levels of the VLBW children were presented earlier, in relation to blood pressure [4]. The present study focuses on the F/E ratio and the comparison to term-born AGA children.

\section{Methods}

\section{Study Population}

The VLBW infants were part of the Neonatal Insulin Replacement Therapy in Europe (NIRTURE) trial, an international multicenter randomized controlled trial investigating the role of early insulin therapy in VLBW infants [8]. After written informed consent was obtained from both parents, VLBW infants younger than $24 \mathrm{~h}$ of age and requiring intensive care were randomized to receive continuous intravenous infusion of insulin for the first 7 days of life or standard neonatal care with insulin treatment only in case of hyperglycemia. Exclusion criteria included maternal diabetes and major congenital anomalies. All infants participating in the NIRTURE trial in our neonatal intensive care unit (inclusion period from 2006 to 2007) were eligible for the present study. Therefore, the sample size of the VLBW infants in the present study was determined by the number of infants we included in the NIRTURE trial. The results of the NIRTURE trial did not show short-term clinical benefits of early insulin therapy [8]; long-term results have not yet been published.
The term infants were born between 2000 and 2005 from a lowrisk population of pregnant women included in the first trimester in a prospective longitudinal study (Trophoblast study) which aimed to investigate the use of circulating trophoblast for prenatal diagnosis of pregnancy-associated diseases such as preeclampsia [9]. Only term infants born AGA were included in the present study. AGA was defined as a birthweight above the 10th percentile [10]. Standard deviation scores of birthweight were calculated according to Niklasson et al. [11]. Approval from the ethics committee of the VU University Medical Center was obtained.

During the inclusion period of the NIRTURE trial in our neonatal intensive care unit (21 months), 165 VLBW infants were admitted and the parents of 69 infants were approached regarding participation in the study. The most common reasons for not approaching parents were infants not requiring intensive care or no opportunity to obtain informed consent within the first $24 \mathrm{~h}$ after birth. In our unit, 47 VLBW infants participated in the NIRTURE trial. Five infants died and 1 child was excluded because parents refused blood sampling at the follow-up visits; 41 VLBW children were included in the present study. At 2-year corrected age, one of these 41 children was lost to follow-up. Four (10\%) of the VLBW children were SGA (defined as a birthweight below the 10th percentile [10]). Thirty-nine infants received antenatal steroids $1(n=$ $13), 2(n=24)$, or $3(n=2)$ doses of betamethasone intramuscularly and 2 received postnatal steroids (hydrocortisone). Seventeen infants ( 9 male/ 8 female) were assigned to the early-insulin group and 24 infants (12 male/12 female) received standard neonatal care. During the first week of life, 6 infants in the standard care group were treated with insulin for 1 or 2 days because of hyperglycemia due to sepsis.

Ninety term born infants were included in the follow-up part of the Trophoblast study of whom 72 were AGA. Eight AGA children were excluded from the present study because they were lost to follow-up after the first visit at 3 months of age; 64 children were included in the present study. At 2 years of age, 6 children were lost to follow-up.

\section{Data Collection}

The VLBW infants visited the outpatient clinic at expected date of delivery and at the corrected ages of 3 and 6 months and 1 year and 2 years, the term born infants at 3 months, 1 year, and 2 years of age, according to the protocol of the NIRTURE trial and Trophoblast study, respectively. At each visit, anthropometry according to Dauncey et al. [12] was performed by the same trained research nurse in all children. Standard deviation scores of weight, height, head circumference, and BMI were calculated according to Dutch references $[13,14]$.

Blood samples for measurement of cortisol and cortisone were taken at 6 months and 2 years of corrected age in the VLBW infants and at 3 months and 1 and 2 years of age in the term born infants, according to the specific study protocol.

Blood samples taken at 2 years of (corrected) age were also used for measurement of total cholesterol, HDL cholesterol, triglycerides, glucose, and insulin. Insulin resistance was estimated by the homeostatic model assessment for insulin resistance (HOMA$\mathrm{IR}=$ [fasting insulin $\mathrm{mU} / \mathrm{L} \times$ fasting glucose $\mathrm{mmol} / \mathrm{L}] / 22.5)$ [15].

All blood samples were taken early in the afternoon after a fasting period of at least $3 \mathrm{~h}$. Samples were stored at $-80^{\circ} \mathrm{C}$ and were all analyzed at the same time. Study population and data collection also have been previously described $[3,4,16,17]$. 
Table 1. Characteristics of the VLBW and term AGA children

\begin{tabular}{|c|c|c|c|}
\hline & $\operatorname{VLBW}(n=41)$ & Term AGA $(n=64)$ & $p$ value \\
\hline Sex & $21 \mathrm{M} / 20 \mathrm{~F}$ & $35 \mathrm{M} / 29 \mathrm{~F}$ & 0.73 \\
\hline Gestational age, weeks & $27.9 \pm 1.3$ & $39.3 \pm 1.2$ & $<0.001$ \\
\hline Birthweight, g & $1,059 \pm 231$ & $3,529 \pm 393$ & $<0.001$ \\
\hline Birthweight SDS & $-0.06 \pm 0.9$ & $0.3 \pm 0.7$ & 0.02 \\
\hline Maternal age, years & $31.3 \pm 4.7$ & $33.7 \pm 4.4$ & 0.01 \\
\hline Maternal weight, $\mathrm{kg}$ & $68.2 \pm 13.7$ & $71.7 \pm 13.2$ & 0.21 \\
\hline Maternal smoking & $5 / 41(12 \%)$ & $6 / 64(9 \%)$ & 0.75 \\
\hline Racial group & $\begin{array}{l}26 \text { Caucasians, } 10 \text { Blacks, } 3 \text { Moroccans, } \\
\text { and } 2 \text { Asians }\end{array}$ & $\begin{array}{l}55 \text { Caucasians, } 4 \text { Blacks, and } \\
5 \text { Asians }\end{array}$ & \\
\hline Highest level of parental education ${ }^{a}$ & 3 low, 18 medium, and 20 high & $\begin{array}{l}1 \text { low, } 19 \text { medium, } 35 \text { high, } \\
\text { and } 9 \text { unknown }\end{array}$ & \\
\hline Breastfeeding & $31 / 41(76 \%)$ & $45 / 64(70 \%)$ & 0.55 \\
\hline Duration of exclusive breastfeeding, months & $3(0-8)$ & $3(0-6)$ & 0.21 \\
\hline Total duration of breastfeeding, months & $5(1-23)$ & $4(1-24)$ & 0.92 \\
\hline Weight, $g$ at expected date of delivery ${ }^{b}$ & $3,154 \pm 579$ & & $<0.001$ \\
\hline Weight SDS at expected date of delivery ${ }^{\mathrm{b}}$ & $-1.2 \pm 1.3$ & & $<0.001$ \\
\hline
\end{tabular}

Data are expressed as mean \pm standard deviation, percentages or numbers; duration of breastfeeding is presented as median (range). VLBW infants are compared to term AGA infants. VLBW, very low birthweight; AGA, appropriate for gestational age. ${ }^{a}$ Highest level of education completed by either parent was used as an indicator of socioeconomic status and classified as low (primary school, low occupational training), medium (high school, medium occupational training) or high (high occupational training, university). ${ }^{\mathrm{b}}$ Weight (SDS) at expected date of delivery of the VLBW infants was compared to birthweight (SDS) of the term AGA infants.

\section{Assays}

For measurement of serum cortisol and cortisone samples were prepared as described by Hawley et al. [18]; concentrations were assessed by the isotope dilution LC-tandem MS method as described in detail by van der Voorn et al. [19, 20]. Total cholesterol, HDL cholesterol, and triglycerides were measured by enzymatic colorimetric assay (CHOD-PAP, HDL-C plus, and GPO-PAP, respectively; Modular Analytics, Roche Diagnostics, Mannheim, Germany). Inter-assay coefficient of variation is $1.9 \%$ at both 3.5 $\mathrm{mmol} / \mathrm{L}$ and $7.1 \mathrm{mmol} / \mathrm{L}$ for total cholesterol, $2.9 \%$ at $1.0 \mathrm{mmol} / \mathrm{L}$ and $2.8 \%$ at $2.4 \mathrm{mmol} / \mathrm{L}$ for HDL cholesterol, and $3.0 \%$ at 1.1 $\mathrm{mmol} / \mathrm{L}$ and $2.3 \%$ at $1.9 \mathrm{mmol} / \mathrm{L}$ for triglycerides.

Glucose concentrations were measured by the hexokinase method (Modular Analytics, Roche Diagnostics, Mannheim, Germany). Inter-assay coefficient of variation is $2.0 \%$ at $4.8 \mathrm{mmol} / \mathrm{L}$ and $1.8 \%$ at $19.8 \mathrm{mmol} / \mathrm{L}$.

Insulin was measured by immunometric assay (Advia Centaur, Siemens Medical Solutions Diagnostics, Malvern, PA, USA). Lower limit of quantitation is $10 \mathrm{pmol} / \mathrm{L}$; intra-assay coefficient of variation is $4 \%$ at $20 \mathrm{pmol} / \mathrm{L}, 3 \%$ at $500 \mathrm{pmol} / \mathrm{L}$, and $4 \%$ at 1,500 $\mathrm{pmol} / \mathrm{L}$; inter-assay coefficient of variation is $8 \%$ at $24 \mathrm{pmol} / \mathrm{L}$ and $7 \%$ at both $780 \mathrm{pmol} / \mathrm{L}$ and 3,000 pmol/L. For insulin levels below the limit of quantitation a value of $1 \mathrm{pmol} / \mathrm{L}$ was used.

\section{Statistical Analysis}

Statistical analyses were performed using the Statistical Package of Social Sciences software for Microsoft Windows version 19 (SPSS inc., Chicago, IL, USA) and Stata version 14 (StataCorp, College Station, TX, USA). Differences in characteristics between VLBW children and term AGA children were evaluated using in- dependent Student's $t$ test for normally distributed variables, Mann-Whitney test for not normally distributed variables, and $\chi^{2}$ tests for dichotomous and categorical variables. Longitudinal differences in serum cortisol, cortisone, and F/E ratio between the VLBW children and term AGA children and between the subgroups of VLBW children (boys vs. girls and early insulin vs. standard care) were analyzed with linear mixed model analyses. Linear mixed model analyses were used to adjust for the dependency of the observations within the child.

Bivariate correlation analysis was performed to study the relation between $\mathrm{F} / \mathrm{E}$ ratio and several components of the metabolic syndrome and between $\mathrm{F} / \mathrm{E}$ ratio and growth parameters.

Both cortisol and cortisone were log transformed before analyses and all analyses were (if possible) adjusted for gender. $p$ values $<0.05$ were considered as significant.

\section{Results}

Table 1 shows the characteristics of the VLBW infants and term AGA infants including parental background information. Anthropometric data were reported earlier [17].

\section{Cortisol and Cortisone}

Table 2 shows serum cortisol, serum cortisone, and $\mathrm{F} / \mathrm{E}$ ratio for the VLBW and term AGA children. At 2 
Table 2. Serum cortisol, cortisone, and ratio

$\begin{array}{ll}\text { VLBW } & \text { Term AGA } \\ (n=41) & (n=64)\end{array}$

\begin{tabular}{|c|c|c|}
\hline \multicolumn{3}{|l|}{ At 3 months of (corrected) as } \\
\hline Cortisol, nmol/L & & $255(135-389)$ \\
\hline Cortisone, $\mathrm{nmol} / \mathrm{L}$ & & $89(65-105)$ \\
\hline Ratio cortisol/cortisone & & $2.8(1.9-3.6)$ \\
\hline \multicolumn{3}{|l|}{ At 6 months of (corrected) age } \\
\hline Cortisol, nmol/L & \multicolumn{2}{|l|}{$215(161-295)$} \\
\hline Cortisone, $\mathrm{nmol} / \mathrm{L}$ & \multicolumn{2}{|l|}{$65(49-78)$} \\
\hline Ratio cortisol/cortisone & \multicolumn{2}{|l|}{$3.7(2.9-4.3)$} \\
\hline \multicolumn{3}{|l|}{ At 1 year of (corrected) age } \\
\hline Cortisol, $\mathrm{nmol} / \mathrm{L}$ & & $245(197-319)$ \\
\hline nmol/L & & $58(40-73)$ \\
\hline Ratio cortisol/cortisone & & $4.3(3.7-5.2)$ \\
\hline \multicolumn{3}{|l|}{ At 2 years of (corrected) age } \\
\hline Cortisol, nmol/L & $200(153-348)$ & $243(176-296)$ \\
\hline Cortisone, $\mathrm{nmol} / \mathrm{L}$ & $47(33-72)$ & $61(44-70)$ \\
\hline Ratio cortisol/cortisone & $4.7(4.0-6.1)$ & $4.1(3.5-5.0)$ \\
\hline \multicolumn{3}{|c|}{$\begin{array}{l}\text { Difference between the VLBW and term AGA children on } \\
\text { average over time adjusted for gender }\end{array}$} \\
\hline Cortisol, nmol/L & \multicolumn{2}{|c|}{$0.99^{\mathrm{a}}(0.79-1.22) ; p=0.89$} \\
\hline Cortisone, $\mathrm{nmol} / \mathrm{L}$ & \multicolumn{2}{|c|}{$0.88^{\mathrm{a}}(0.75-1.03) ; p=0.10$} \\
\hline Ratio cortisol/cortisone & \multicolumn{2}{|c|}{$0.62^{\mathrm{b}}(0.06-1.19) ; p=0.03$} \\
\hline
\end{tabular}

Data are expressed as median and interquartile range. ${ }^{a}$ Difference expressed as a ratio (95\% confidence interval) (VLBW compared to term AGA; VLBW, lower values than term AGA). ${ }^{\mathrm{b}} \mathrm{Un}$ standardized regression coefficient obtained from a mixed-model analysis.

years of (corrected) age, $\mathrm{F} / \mathrm{E}$ ratio was significantly higher in VLBW children compared to term AGA children $(p=$ 0.039 ). Longitudinal analysis showed that on average over the first 2 years of life, F/E ratio was significantly higher in VLBW children compared to term AGA children. Serum cortisol and cortisone did not differ significantly between the VLBW and term AGA children over time.

In VLBW children, cortisone at 2 years of corrected age was significantly lower than that at 6 months of corrected age $(p=0.008)$ and $\mathrm{F} / \mathrm{E}$ ratio was significantly higher at 2 years compared to 6 months of corrected age $(p<$ $0.001)$. In term AGA children, cortisone at 1 year of age was significantly lower than that at 3 months of age $(p<$ 0.001 ) and $F / E$ ratio was significantly higher at 1 year compared to 3 months of age.

Table 3 shows serum cortisol and cortisone in subgroups of VLBW children. Longitudinal analysis showed that on average over the first 2 years of life, both cortisol and cortisone were significantly higher in the early-insulin group compared to the standard care group. F/E ratio did not differ between these two groups. We did not find significant differences between VLBW boys and girls. Adjustment for the number of doses of antenatal steroids did not influence these results.

\section{Relation of F/E Ratio to Metabolic Syndrome Components}

Descriptive information regarding metabolic syndrome components at 2 years of (corrected) age was reported earlier [16]. In the total group of children (VLBW and term AGA), F/E ratio was significantly correlated to triglycerides $(r=0.22 ; p=0.036)$ at 2 years of (corrected) age. $\mathrm{F} / \mathrm{E}$ ratio was not correlated to total cholesterol, $\mathrm{HDL}$ cholesterol, glucose, insulin, and HOMA-IR.

\section{Relation of F/E Ratio to Growth Parameters}

In the total group of children (VLBW and term AGA), $\mathrm{F} / \mathrm{E}$ ratio was significantly correlated to weight $(r=-0.25$; $p=0.017)$ and BMI $(r=-0.23 ; p=0.026)$ at 2 years of (corrected) age. F/E ratio was not significantly correlated to length at 2 years of (corrected) age.

\section{Discussion}

The present study shows that during the first 2 years of life $\mathrm{F} / \mathrm{E}$ ratio is significantly higher in VLBW children compared to term AGA children. Insulin-treated VLBW children have higher serum cortisol and cortisone levels during the first 2 years of life than VLBW children in the standard care group.

In healthy subjects, $\mathrm{F} / \mathrm{E}$ ratio rises during the first year of life, stays unchanged until adulthood and then increases with age. The increase of $\mathrm{F} / \mathrm{E}$ ratio indicates a decrease in $11 \beta$-HSD2 activity and may contribute to the increase of blood pressure in early childhood and in elderly persons $[21,22]$. This is in accordance with the results of the present study, we also found an increase in $\mathrm{F} / \mathrm{E}$ ratio in early childhood, in both VLBW children and term AGA children.

Early programming of the HPA axis probably plays an important role in the later metabolic and cardiovascular consequences of preterm birth. In childhood, pretermborn infants have reduced insulin sensitivity and raised blood pressure [23-25]. Several studies show higher salivary cortisol levels in preterm born children aged 5-14 years compared to term-born controls [26-28] and cortisol levels are positively correlated to blood pressure in children [29], indicating the role of programming of the HPA axis. Besides these indications for increased activity 
Table 3. Serum cortisol, cortisone, and ratio in subgroups of VLBW children

\begin{tabular}{|c|c|c|c|c|}
\hline & $\begin{array}{l}\text { Girls } \\
(n=20)\end{array}$ & $\begin{array}{l}\text { Boys } \\
(n=21)\end{array}$ & $\begin{array}{l}\text { Standard care } \\
(n=24)\end{array}$ & $\begin{array}{l}\text { Early insulin } \\
(n=17)\end{array}$ \\
\hline \multicolumn{5}{|l|}{ At 6 months of corrected age } \\
\hline Cortisone, $\mathrm{nmol} / \mathrm{L}$ & $71(53-83)$ & $64(45-75)$ & $63(49-76)$ & $69(44-82)$ \\
\hline Ratio cortisol/cortisone & $3.8(3.0-4.3)$ & $3.7(2.6-4.3)$ & $3.7(2.8-4.1)$ & $3.8(3.2-4.6)$ \\
\hline \multicolumn{5}{|l|}{ At 2 years of corrected age } \\
\hline Cortisone, $\mathrm{nmol} / \mathrm{L}$ & $44(31-72)$ & $47(37-75)$ & $36(31-50)$ & $72(50-77)$ \\
\hline Ratio cortisol/cortisone & $4.7(3.9-6.2)$ & $4.8(4.2-6.0)$ & $4.6(3.9-5.7)$ & $5.2(4.0-6.2)$ \\
\hline \multicolumn{5}{|c|}{ Difference between the groups on average over time } \\
\hline Cortisol serum, nmol/L & \multicolumn{2}{|c|}{$0.99^{\mathrm{a}}(0.78-1.36) ; p=0.93$} & \multicolumn{2}{|c|}{$1.39^{\mathrm{a}}(1.12-1.75) ; p=0.003$} \\
\hline Cortisone serum, $\mathrm{nmol} / \mathrm{L}$ & \multicolumn{2}{|c|}{$0.99^{\mathrm{a}}(0.82-1.19) ; p=0.90$} & \multicolumn{2}{|c|}{$1.28^{\mathrm{a}}(1.08-1.53) ; p=0.005$} \\
\hline Ratio cortisol/cortisone & \multicolumn{2}{|c|}{$0.09^{\mathrm{b}}(-0.59$ to 0.72$) ; p=0.80$} & \multicolumn{2}{|c|}{$0.31^{\mathrm{b}}(-0.38$ to 0.99$) ; p=0.38$} \\
\hline
\end{tabular}

Data are expressed as median and interquartile range. VLBW, very low birthweight. ${ }^{\text {a }}$ Difference expressed as a ratio (95\% confidence interval) (boys vs. girls and early insulin vs. standard care). ${ }^{b}$ Unstandardized regression coefficient obtained from a mixed-model analysis.

of the HPA axis based on basal cortisol levels, studies investigating cortisol reactivity to stress suggest lower HPA axis response to psychosocial stress in VLBW young adults [30] and to immunization pain in preterm-born boys at 4 months of corrected age [31], both compared to termborn controls. Cumulative cortisol levels in hair at 7 years of age were found to be lower in preterm-born children compared to term-born controls [32]. Taken together, these studies suggest dysregulation in cortisol levels in preterm-born children compared to term-born controls.

Some of the components of the metabolic syndrome can already be detected at preschool age in preterm-born children. We showed earlier that at 2 years of corrected age VLBW children have significantly higher glucose levels than 2-year-old term-born AGA children [16]. Blood pressure is already elevated in early childhood in VLBW infants [1-3]. The positive correlation between serum cortisol and blood pressure we showed earlier in VLBW boys at 2 years of corrected age suggests the contribution of programming of the HPA axis already in early childhood [4]. In accordance with this, Grunau et al. [33] showed that preterm infants born at less than 28 weeks of gestational age had significantly higher basal salivary cortisol levels at 8 and 18 months of corrected age compared to term-born infants.

In the present study, serum cortisol levels were not higher in VLBW infants, but over the first 2 years of life, $\mathrm{F} / \mathrm{E}$ ratio was higher in VLBW children compared to term AGA children. As far as we know, F/E ratio has not been investigated earlier in early childhood in VLBW infants.
Houang et al. [5] studied F/E ratio in IUGR-born children without catch-up growth at 1.1-13.5 years of age. They showed that $20 \%$ of these children had high $\mathrm{F} / \mathrm{E}$ ratios compared to controls, suggesting partial $11 \beta$-HSD2 deficit, and that high F/E ratio was associated with high cholesterol levels and high blood pressure [5]. In another study in SGA-born children at the age of 12 years, high $\mathrm{F} / \mathrm{E}$ ratio was associated with high LDL cholesterol and high HOMA-IR [6]. Considering these associations with cholesterol, blood pressure, and insulin resistance, high $\mathrm{F} / \mathrm{E}$ ratio probably indicates a risk factor for cardiovascular disease in later life. Higher F/E ratio could not only be caused by decreased $11 \beta$-HSD2 activity but also by increased activity of $11 \beta$-hydroxysteroid dehydrogenase type 1 (11 -HSD1), which converts cortisone into cortisol and is mainly active in the liver [21]. However, in rats, maternal malnutrition during pregnancy results in raised systolic blood pressure and markedly reduced levels of $11 \beta$-HSD2 expression in the kidney and adrenal of the offspring; levels of $11 \beta$-HSD1 expression remain unchanged. This indicates that expression of $11 \beta-H S D 2$, and not $11 \beta$-HSD1, is involved in long-term programming of glucocorticoid hormone action [34].

The results of our present study therefore suggest that in VLBW infants, low $11 \beta-H S D 2$ activity could contribute to the long-term metabolic and cardiovascular risks. The negative effect of cortisol on insulin sensitivity probably plays a crucial role in the association between high $\mathrm{F} / \mathrm{E}$ ratio and metabolic and cardiovascular consequences $[35,36]$. 
In SGA born children, $\mathrm{F} / \mathrm{E}$ ratio is positively correlated with total and LDL cholesterol levels $[5,6]$. In our total group of children (VLBW and term AGA), F/E ratio at 2 years of (corrected) age was positively correlated with triglycerides. This could indicate that F/E ratio, and hence $11 \beta$-HSD2 activity, is associated with metabolic risks.

Decreased $11 \beta$-HSD2 activity is also associated with reduced (catch-up) growth in childhood, probably due to glucocorticoid imbalance; in SGA-born children, F/E ratio is negatively correlated with height $[5,6]$. We also found an inverse relation between $\mathrm{F} / \mathrm{E}$ ratio and growth: in our total group of children, there was a negative correlation between $\mathrm{F} / \mathrm{E}$ ratio and weight and between $\mathrm{F} / \mathrm{E}$ ratio and BMI.

We earlier showed that VLBW children treated with insulin in the first postnatal week have higher serum cortisol levels at 2 years of corrected age than children treated with standard care [4]. In the present study, we investigated the longitudinal differences between the two groups during early childhood and found that both cortisol and cortisone were higher in the early-insulin group compared to the standard care group. This confirms that early insulin treatment may affect the programming of the HPA axis as we suggested earlier [4]. F/E ratio was not different between the early-insulin and standard care group, so early insulin treatment itself appears to have no additional effect on $11 \beta$-HSD2 activity.

Our study is limited by the small number of children. This could explain why we did not find higher cortisol levels in VLBW children in contrast to other studies [26$28,33]$. Further studies are necessary to provide more clarity about cortisol, cortisone, and the $\mathrm{F} / \mathrm{E}$ ratio in VLBW children. Cortisol, cortisone, and F/E ratio should be measured in larger groups of VLBW and term-born children, at the same time points, in early and later childhood, in order to confirm the difference in $\mathrm{F} / \mathrm{E}$ ratio suggested by the results of the present study and to find out whether a higher F/E ratio persists in older children. Future studies should also include measurement of growth parameters and of several metabolic syndrome components, including blood pressure, at several time points in order to further investigate the relationship between $\mathrm{F} / \mathrm{E}$ ratio and metabolic parameters in children and between $\mathrm{F} / \mathrm{E}$ ratio and growth.

In conclusion, VLBW infants have higher $\mathrm{F} / \mathrm{E}$ ratio during early childhood compared to term-born children, suggesting lower $11 \beta$-HSD2 activity. This could contribute to the long-term metabolic and cardiovascular risks. In VLBW infants, early insulin treatment could affect the programming of the HPA axis, resulting in higher cortisol and cortisone levels during early childhood.

\section{Statement of Ethics}

The VLBW infants were part of the randomized controlled Neonatal Insulin Replacement Therapy in Europe (NIRTURE) trial (EudraCT number 2004-002170-34). Written informed consent was obtained from both parents. Approval from the ethics committee of the VU University Medical Center was obtained (No. 2004/121).

\section{Conflict of Interest Statement}

The authors have no conflicts of interest to declare.

\section{Funding Sources}

The authors did not receive any funding.

\section{Author Contributions}

M.d.J.: conception and design, data collection, analysis and interpretation of data, writing original draft, and review and editing of the manuscript. A.C.: data collection and review and editing of the manuscript. J.T.: statistical analysis and review and editing of the manuscript. M.v.W.: conception and design, analysis and interpretation of data, review and editing of the manuscript, and supervision.

\section{References}

1 Duncan AF, Heyne RJ, Morgan JS, Ahmad N, Rosenfeld CR. Elevated systolic blood pressure in preterm very-low-birth-weight infants $\leq 3$ years of life. Pediatr Nephrol. 2011 Jul; 26(7):1115-21.

2 Bonamy AK, Källén K, Norman M. High blood pressure in 2.5-year-old children born extremely preterm. Pediatrics. 2012 May; 129(5):e1199-204.
3 de Jong M, Lafeber HN, Cranendonk A, van Weissenbruch MM. Components of the metabolic syndrome in early childhood in verylow-birth-weight infants. Horm Res Paediatr. 2014;81(1):43-9.

4 de Jong M, Cranendonk A, van Weissenbruch MM. Salivary and serum cortisol and relation to blood pressure in infancy and early childhood in very-low-birth-weight infants. Pediatr Res. 2015 Oct; 78(4):476-9. 
5 Houang M, Morineau G, le Bouc Y, Fiet J, Gourmelen M. The cortisol-cortisone shuttle in children born with intrauterine growth retardation. Pediatr Res. 1999 Aug;46(2):189_ 93.

6 Tenhola S, Turpeinen U, Halonen P, Hämäläinen E, Voutilainen R. Association of serum lipid concentrations, insulin resistance index and catch-up growth with serum cortisol/cortisone ratio by liquid chromatography tandem mass spectrometry in children born small for gestational age. Pediatr Res. 2005 Sep;58(3):467-71.

7 Whitworth JA, Stewart PM, Burt D, Atherden SM, Edwards CR. The kidney is the major site of cortisone production in man. Clin Endocrinol. 1989 Sep;31(3):355-61.

8 Beardsall K, Vanhaesebrouck S, Ogilvy-Stuart AL, Vanhole C, Palmer CR, van Weissenbruch $\mathrm{M}$, et al. Early insulin therapy in verylow-birth-weight infants. N Engl J Med. 2008 Oct;359(18):1873-84.

9 Tjoa ML, van Vugt JM, Go AT, Blankenstein MA, Oudejans CB, van Wijk IJ. Elevated Creactive protein levels during first trimester of pregnancy are indicative of preeclampsia and intrauterine growth restriction. J Reprod Immunol. 2003 Jun;59(1):29-37.

10 Pollack RN, Divon MY. Intrauterine growth retardation: definition, classification, and etiology. Clin Obstet Gynecol. 1992 Mar;35(1): 99-107.

11 Niklasson A, Ericson A, Fryer JG, Karlberg J, Lawrence C, Karlberg P. An update of the swedish reference standards for weight, length and head circumference at birth for given gestational age (1977-1981). Acta Paediatr Scand. 1991 Aug-Sep;80(8-9):756-62.

12 Dauncey MJ, Gandy G, Gairdner D. Assessment of total body fat in infancy from skinfold thickness measurements. Arch Dis Child. 1977 Mar;52(3):223-7.

13 Fredriks AM, van Buuren S, Burgmeijer RJ, Meulmeester JF, Beuker RJ, Brugman E, et al. Continuing positive secular growth change in The Netherlands 1955-1997. Pediatr Res. 2000 Mar;47(3):316-23.

14 Fredriks AM, van Buuren S, Wit JM, Verloove-Vanhorick SP. Body index measurements in 1996-7 compared with 1980. Arch Dis Child. 2000 Feb;82(2):107-12.

15 Matthews DR, Hosker JP, Rudenski AS, Naylor BA, Treacher DF, Turner RC. Homeostasis model assessment: insulin resistance and beta-cell function from fasting plasma glucose and insulin concentrations in man. Diabetologia. 1985 Jul;28(7):412-9.
16 de Jong M, Cranendonk A, van Weissenbruch MM. Components of the metabolic syndrome in early childhood in very-low-birth-weight infants and term small and appropriate for gestational age infants. Pediatr Res. 2015 Oct; 78(4):457-61.

17 de Jong M, Cranendonk A, Twisk JW, van Weissenbruch MM. IGF-I and relation to growth in infancy and early childhood in very-low-birth-weight infants and term born infants. PLoS One. 2017;12(2):e0171650.

18 Hawley JM, Owen LJ, MacKenzie F, Mussell C, Cowen S, Keevil BG. Candidate reference measurement procedure for the quantification of total serum cortisol with LC-MS/MS. Clin Chem. 2016 Jan;62(1):262-9.

19 van der Voorn B, Martens F, Peppelman NS, Rotteveel J, Blankenstein MA, Finken MJ, et al. Determination of cortisol and cortisone in human mother's milk. Clin Chim Acta. 2015 Apr 15;444:154-5.

20 van der Voorn B, de Waard M, van Goudoever JB, Rotteveel J, Heijboer AC, Finken MJ. Breast-milk cortisol and cortisone concentrations follow the diurnal rhythm of maternal hypothalamus-pituitary-adrenal axis activity. J Nutr. 2016 Nov;146(11):2174-9.

21 Dotsch J, Hohenberger I, Peter M, Sippell W, Dorr HG. Evidence for change of 11beta-hydroxysteroid dehydrogenase activity during infancy and childhood. Pediatr Res. 2000 Nov;48(5):697-700.

22 Campino C, Martinez-Aguayo A, Baudrand $\mathrm{R}$, Carvajal CA, Aglony M, Garcia H, et al. Age-related changes in $11 \beta$-hydroxysteroid dehydrogenase type 2 activity in normotensive subjects. Am J Hypertens. 2013 Apr; 26(4):481-7.

23 Hofman PL, Regan F, Jackson WE, Jefferies C, Knight DB, Robinson EM, et al. Premature birth and later insulin resistance. N Engl J Med. 2004 Nov;351(21):2179-86.

24 Bonamy AK, Martin H, Jörneskog G, Norman M. Lower skin capillary density, normal endothelial function and higher blood pressure in children born preterm. J Intern Med. 2007 Dec;262(6):635-42.

25 Kist-van Holthe JE, van Zwieten PH, SchellFeith EA, Zonderland HM, Holscher HC, Wolterbeek R, et al. Is nephrocalcinosis in preterm neonates harmful for long-term blood pressure and renal function? Pediatrics. 2007 Mar;119(3):468-75.

26 Buske-Kirschbaum A, Krieger S, Wilkes C, Rauh W, Weiss S, Hellhammer DH. Hypothalamic-pituitary-adrenal axis function and the cellular immune response in former preterm children. J Clin Endocrinol Metab. 2007 Sep; 92(9):3429-35.
27 de Graaf J, van den Akker EL, van Lingen RA, Groot Jebbink LJ, de Jong FH, Grunau RE, et al. Five-year follow-up of effects of neonatal intensive care and morphine infusion during mechanical ventilation on diurnal cortisol rhythm. J Pediatr. 2014 Sep;165(3):459-63.e2.

28 Brummelte S, Chau CM, Cepeda IL, Degenhardt A, Weinberg J, Synnes AR, et al. Cortisol levels in former preterm children at school age are predicted by neonatal procedural pain-related stress. Psychoneuroendocrinology. 2015 Jan;51:151-63.

29 Martinez-Aguayo A, Aglony M, Bancalari R, Avalos C, Bolte L, Garcia H, et al. Birth weight is inversely associated with blood pressure and serum aldosterone and cortisol levels in children. Clin Endocrinol. 2012 May;76(5):713-8.

30 Kaseva N, Wehkalampi K, Pyhälä R, Moltchanova E, Feldt K, Pesonen AK, et al. Blunted hypothalamic-pituitary-adrenal axis and insulin response to psychosocial stress in young adults born preterm at very low birth weight. Clin Endocrinol. 2014 Jan;80(1):101-6.

31 Grunau RE, Tu MT, Whitfield MF, Oberlander TF, Weinberg J, Yu W, et al. Cortisol, behavior, and heart rate reactivity to immunization pain at 4 months corrected age in infants born very preterm. Clin J Pain. 2010 Oct; 26(8):698-704.

32 Grunau RE, Cepeda IL, Chau CM, Brummelte S, Weinberg J, Lavoie PM, et al. Neonatal painrelated stress and NFKBIA genotype are associated with altered cortisol levels in preterm boys at school age. PLoS One. 2013 Sep;8(9):e73926.

33 Grunau RE, Haley DW, Whitfield MF, Weinberg J, Yu W, Thiessen P. Altered basal cortisol levels at 3, 6, 8 and 18 months in infants born at extremely low gestational age. J Pediatr. 2007 Feb;150(2):151-6.

34 Bertram C, Trowern AR, Copin N, Jackson AA, Whorwood CB. The maternal diet during pregnancy programs altered expression of the glucocorticoid receptor and type 211 beta-hydroxysteroid dehydrogenase: potential molecular mechanisms underlying the programming of hypertension in utero. Endocrinology. 2001 Jul;142(7):2841-53.

35 Phillips DI, Barker DJ, Fall CH, Seckl JR, Whorwood CB, Wood PJ, et al. Elevated plasma cortisol concentrations: a link between low birth weight and the insulin resistance syndrome? J Clin Endocrinol Metab. 1998 Mar;83(3):757-60.

36 Rosmond R, Dallman MF, Björntorp P. Stress-related cortisol secretion in men: relationships with abdominal obesity and endocrine, metabolic and hemodynamic abnormalities. J Clin Endocrinol Metab. 1998 Jun; 83(6):1853-9. 